Discussion Paper No. 08-006

\title{
Distributional and Behavioural Effects of the German Labour Market Reform
}

Markus Clauss and Reinhold Schnabel

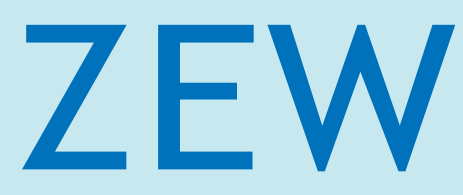

Zentrum für Europäische Wirtschaftsforschung $\mathrm{GmbH}$

Centre for European

Economic Research 
Discussion Paper No. 08-006

\title{
Distributional and Behavioural Effects of the German Labour Market Reform
}

\author{
Markus Clauss and Reinhold Schnabel
}

Download this ZEW Discussion Paper from our ftp server:

ftp://ftp.zew.de/pub/zew-docs/dp/dp08006.pdf

Die Discussion Papers dienen einer möglichst schnellen Verbreitung von neueren Forschungsarbeiten des ZEW. Die Beiträge liegen in alleiniger Verantwortung der Autoren und stellen nicht notwendigerweise die Meinung des ZEW dar.

Discussion Papers are intended to make results of ZEW research promptly available to other economists in order to encourage discussion and suggestions for revisions. The authors are solely responsible for the contents which do not necessarily represent the opinion of the ZEW. 


\section{Non-technical summary}

We estimate the effects of the introduction of the Unemployment Benefit II (UBII) as reform of the German Unemployment Insurance that replaced the wage related Unemployment Assistance with an income maintenance program and stronger means testing.

We model the German tax-benefit system and use the waves of the German SocioEconomic Panel (GSOEP) for 2004 and 2005. We define the "Group A" as people who are "Affected" by the reform. Within this Group A, we also subsume people who were not eligible to any benefits in the status quo and who become eligible after the reform.

The aim of the paper is twofold. First we are interested in the distributional effects of the reform for the entire population and for several subgroups. Second, we estimate a discrete labour supply model to estimate the labour supply effects. Furthermore we use the estimation results to simulate the distributional effects that correspond to the labour supply effects by applying the pseudo-distribution method.

The introduction of UB II has led to a consolidation of the benefit system. The presumption that people who used to receive high UA-benefits because they had higher earnings (before unemployment) are losing most is confirmed. We find that six deciles (seven deciles) are losing income as a consequence of the reform with consideration of behavioural effects (without behavioural effects). We identify reform winners in the subgroups of (1) former recipients of social assistance and of (2) new recipients. The largest gains accrue to households with many children and to households who have not been eligible for any benefits before. These households become eligible, because of the less restrictive non-earned-income test compared to the old social assistance. For the whole group of benefit recipients, namely "Group A", we find a reduction of the income inequality accompanied by a positive effect on the poverty measures. This effect is in line with the theoretical considerations. The new benefit system has a tendency to equalize the transfer payments on a level that is slightly higher than the old social assistance level. These results are also confirmed by the labour supply effects. We find negative participation effects for women with children in couple and single households. In the opposite, couples without children, single men and women without children increase their participation. These contrary effects nearly cancel out and are not significant in either direction. Thus, the net employment effect of the reform is negligible. 


\title{
Distributional and Behavioural Effects of the German Labour Market Reform
}

\section{Markus Clauss}

ZEW Mannheim, L 7,1, 68161 Mannheim, Germany; email: Clauss@zew.de

\section{Reinhold Schnabel}

ZEW Mannheim, L 7,1, 68161 Mannheim, University Essen-Duisburg, Germany; email: Reinhold.Schnabel@uni-due.de

\begin{abstract}
:
We estimate the effects of the reform of the German Unemployment Insurance that replaced the wage related Unemployment Assistance with an income maintenance program and stronger means testing. We model the tax-benefit system and use the SocioEconomic Panel. We estimate a discrete labour supply model and simulate the behavioural and distributional effects using the pseudo-distribution method. Poverty and inequality decline overall, since households with children and low income gain, while those who used to earn high wages and received high unemployment transfers lose most. The behavioural responses mitigate the redistributive impact of the reform.
\end{abstract}

\section{Key Words:}

distribution analysis, household labour supply, microsimulation, poverty, Germany

\section{JEL Classification:}

D31, I32, J22, H31, I38

This paper originated as part of the project "Developing an IAB-Microsimulaton Model". We are grateful for comments and support from all participants in the joint project. Especially, we would like to thank Juergen Wiemers for support. Furthermore we grateful for comments from the participants of the $1^{\text {st }}$ General Conference of the International Microsimulation Association and the $19^{\text {th }}$ Annual Conference of the European Association of Labour Economists. The usual disclaimer applies. 


\section{INTRODUCTION}

The German labour market reform - which became known as Hartz IV, due to the head of the "Commission to modernize the labour market": Peter Hartz- came into effect on January 1st, 2005. The main feature of this reform is the replacement of the earnings related Unemployment Assistance (UA) with an income maintenance system, called "Unemployment Benefit II" that is unrelated to former earnings. Unemployment Assistance used to be paid to unemployed after their eligibility for Unemployment Benefits (UB) had been exhausted. UB or (UB I as it is called after the reform) was not changed by the reform. It still offers a replacement rate of 60 percent for persons without dependent children and 67 percent for others. The replacement rate of UA used to be 53 percent for persons with dependent children or 50 percent for all others. UA was paid under the condition of a relatively weak means test. The new assistance UB II is basically a redefined Social Assistance (or Welfare program). Thus, it is not related to former wages and it uses a much stricter means test than the old UA. The former Welfare program was also restructured and divided into two branches: (1) Social Assistance for persons temporarily unable to work and (2) "Unemployment Benefits II" for persons considered being labour market participants meaning persons with a capacity to work at least 3 hours a day. Persons who are permanently disabled or retired are covered by a third branch of Social Assistance. The new UB II is, in effect, a minimum income program for all households in which at least one person is considered to be a labour force participant (i.e. working or able to work).

The aim of our study is to evaluate the impact of this reform on the income distribution and on household labour supply. We are interested in the distributional effects for the total population and for several important subgroups such as former recipients of UA or welfare and new recipients of transfers. Since the reform may induce considerable changes in household behaviour, namely labour supply, we also want to capture these effects with our microeconometric model. As a by-product of our analysis, we can characterise changes in labour supply for recipients and non-recipients. These changes in labour supply will in turn change the distributional consequences of the reform. The redistributive effects may be mitigated or exacerbated by the labour supply reactions (provided that changes in labour supply translate into changes in employment).

There have been several previous studies on the distributional effect of the Hartz-IVReform. Schulte (2004) finds that about 59 percent of the former recipients of UA lose income after the reform. Blos and Rudolph (2005), who use the 2003 Income and 
Expenditure Survey, estimate that even two-thirds of former UA-recipients are off worse. Becker and Hauser (2006) use the 2003 waves of the Income and Expenditure Survey and GSOEP arrive at similar conclusions. All three studies have in common that they only consider former recipients of UA and thus only one subgroup that is affected by the reform. They do not consider two important groups: (i) former recipients of Social Assistance (SA) that switch to UB II and (ii) new recipients that become eligible under the new rules. Thus, their distributional analysis remains incomplete. As Blos (2006) shows, based on the Income and Expenditure survey, the number of new transfer recipients reaches about 730,000 households or 1.5 percent of all German households. Moreover, none of the former studies estimates the second-round effects that are induced by changes in labour supply. Thus, they may miss important shifts of the income distribution. Given the recent literature, the contribution of our paper is twofold. First, we extend the analysis to the entire population, yielding a complete description of the income distribution. We can then break down the results into several subgroups. Secondly, we apply a behavioural microsimulation model with an integrated household labour supply model in order to gauge the second-round effects.

Behavioural microsimulation models have been used in many studies of tax-benefit reforms in different countries. Blundell et al. (2000) give an excellent application for the introduction of the Working Families Tax Credit (WFTC) for the UK. For Spain, Labeaga, Olivier and Spadaro (2005) evaluate the likely effects of some changes to the tax-scheme. Other examples are Hoynes (1996), Keane and Moffitt (1998) for the US, Van Soest and Das (2001) for the Netherlands or Aaberge et al. (2000) for Italy, Sweden and Norway. Gerfin and Leu (2003) have determined the impact of in-work benefits on poverty and household labour supply in Switzerland. Beninger et al. (2004) evaluate the effects of replacing the German marital tax splitting with the French family tax splitting. In the context of a distributional analysis, Creedy et al. (2003) have applied a behavioural microsimulation model to simulate distributional and labour supply effects in a discrete hours approach. Creedy et al. (2004) propose the pseudo random distribution method as a superior method to use in distributional analysis. In our distribution analysis, we follow this approach and use the pseudo random distribution method. We extend the ZEW behavioural microsimulation model. Our empirical analysis is based on the 2004 and 2005 waves of the German Socio Economic Panel (GSOEP).

The remainder of this paper is organized as follows. In the following section 2, we present a description of the German labour market reform. In Section 3 we briefly describe the 
dataset, the microsimulation, and the household labour supply model. ${ }^{1}$ In Section 4 we illustrate how we apply our behavioural microsimulation model to conduct an analysis of changes in the income distribution and changes in poverty. The results are presented in Section 5. Section 6 concludes.

\section{THE GERMAN LABOUR MARKET REFORM OF 2005}

\section{The old system before 2005}

The old Unemployment Assistance (UA) was a federal transfer financed by general taxes and administered by the Federal Employment Agency. It was only available for persons who had been eligible for Unemployment Benefits, after eligibility for UB ended. Other unemployed persons or needy households could only apply for Social Assistance. Unemployment Benefits (UB) were only paid for a limited period, depending on the age of the recipient and on the duration of former employment. Unemployment Benefits have not been affected by the reform. However, they are now called "UB I" in order to distinguish them from the new "UB II". The replacement rates of UB are 67 percent for persons with dependent children (irrespective of the number of children) and 60 percent for all others. In the UA, the replacement rates used to be lower at 57 and 53 percent, respectively. Housing allowances were usually paid on top of the unemployment transfers, depending on household composition, income, and rent. If the household income falls short of a minimum income (depending on household composition and rent) additional Social Assistance is paid. Thus, a household with an unemployed person may collect transfers from three different sources: UA/UB, housing allowance, and Social Assistance. At the end of the year 2004, before the reform of the unemployment assistance was enacted, 4.13 million persons between the age of 15 and 65 received Unemployment Assistance and / or Social assistance. Since Social assistance is a residual transfer there were 210,000 persons who received both, UA and Social Assistance, in cases in which UA did not suffice to reach the minimum income level. However, the majority of households with UArecipients made a living above the minimum income level, since $U A$ is usually not the only source of income.

Recipients of UA were subject to a relatively strict earnings test, a less strict income test, and an even weaker wealth test. They could earn up to a maximum of 20 percent of their Unemployment Assistance transfer, or a minimum of 165 Euro. If the information on the

\footnotetext{
${ }^{1}$ See Creedy and Kalb (2005) for a complementary description of the modelling specification.
} 
Unemployment Benefit is missing in our model, we recalculate the potential benefit by multiplying the UA with the factors $60 / 53$ or $67 / 57$ for households with children. The number of working hours was limited to 15 hours per week under UA, and the whole payment was withdrawn as soon as this threshold was reached. There were also special allowances for the recipient's non-earned income and for the partner's income. The wealth test used to be relatively weak compared to the situation after the reform. Recipients of UA were also covered by health and long-term care insurance. Moreover, pension contributions were made on behalf of the recipient. Several social transfers, like child benefits and housing allowances were not counted in the means test. Almost 60 percent of UA recipients received between 300 and 600 Euro per month (Employment Agency, December 2004). About 30 percent of the recipients received between 600 to 900 Euros.

The Social Assistance (SA) supplied a minimum income that was available to all households below a certain minimum income - regardless of the labour force status of the household members. The assistance depends on the number and income of persons in the household sharing their financial resources ("Bedarfsgemeinschaft"). There also existed allowances for earned income up to 50 percent of the standard benefit. After reaching this limit, earned income was taxed away at 100 percent. The allowances for non-earned income were less generous than this. In the case of SA they were also less generous than in the case of UA.

In order to demonstrate the effect of the reform we display stylised budget constraints in the following figures. We show examples single mothers with one child, for recipients of UA and of SA (see Figures 1 and 2), In the left panel of each figure we depict the budget constraints, whereas in the right panel we display the withdrawal rates for earned income. We show the case of a person with a relatively high level of UA of 800 Euro. Thus, this person would belong to the upper quartile of UA recipients. We further assume a gross hourly wage rate of 15 Euro for the case of UA, and of 8 Euro for the case of SA. The monthly rent is set to 280 Euro. 

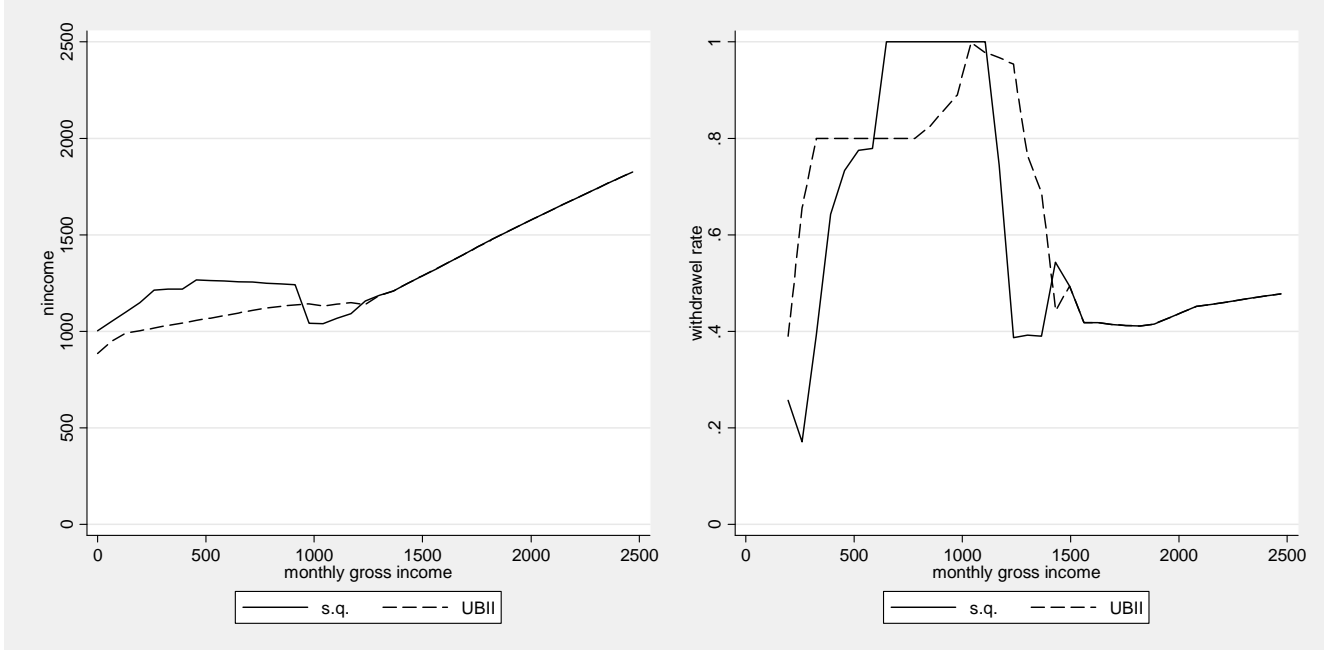

Figure 1: UA-recipients: single mother with one child
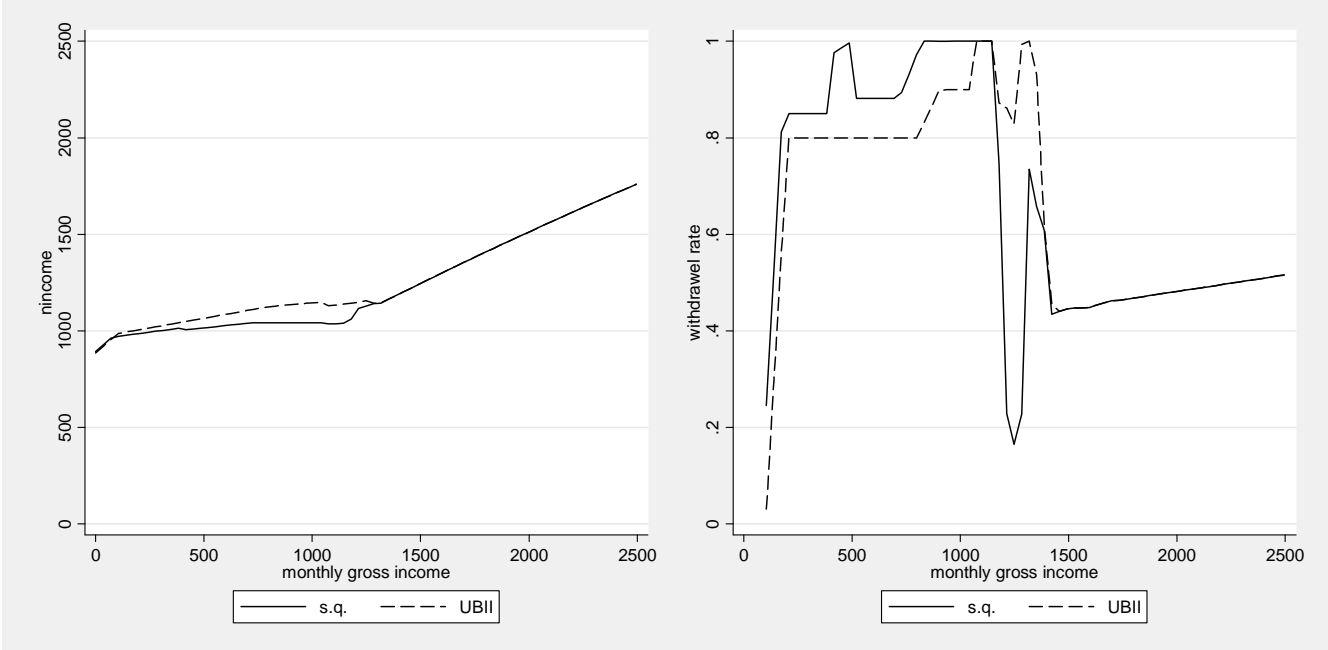

Figure 2: SA-recipients: single mother with one child

\section{Unemployment benefit II}

With the Social Code II the Unemployment Benefit II (UB II) was introduced. It replaces UA and also SA for persons deemed to be labour force participants. It constitutes a "new" basic benefit for the working and the non-working poor. Simultaneously with the Social Code II the Social Code XII was introduced which regulates the new Social Assistance XII that covers the basic needs for persons or households in working age that are not eligible to UB II and are not retired. In order to qualify for UB II it is only required that at least one person in the household is able and willing to work a minimum of three hours a day, is between 15 and 65 years old - besides the income test. The household ("Bedarfsgemeinschaft") comprises parents and their children, married or unmarried partners. The minimum income under UB II is slightly higher than it used to be under the old Social Assistance. This higher amount stems from the fact that transfer money for 
specific needs like new clothes or new household appliances was substituted by a flat amount. $^{2}$ The basic amount is 345 Euro. For each partner or adult child in the household 80 percent of the basic amount are considered. E.g., for a couple without children the minimum income level (net of rent payments) is 621 Euro per month. There are supplementary payments for extraordinary situations (e.g. for single parents, for disabled, for special dietary requirements of sick persons etc.). For children, a lower monthly rate is considered. In general, the rent for "adequate housing" is added. As before 2005, allowances for earned income and for non-earned income exist. Moreover, an additional supplementary child allowance (Kinderzuschlag) was introduced for those "marginal" families who would become eligible for UB II without the additional child allowance. To keep these "marginal" families out of the UB II, the supplementary child allowance is paid in combination with housing benefits. The examples in the Figures 1 and 2 show what effects we can expect: Former recipients of UA will lose a lot of income if they used to receive high UA while former recipients of SA gain income because of the higher benefit rates and the less restrictive income withdrawal rates. In total, we expect a reduction of inequality because as can be seen in the example the budget curves for recipients of UA and SA become equal.

\section{MICROSIMULATION AND ESTIMATION}

In a static microsimulation the so-called "morning after" or "first-round" effect is estimated. It is assumed that the household will not change its behaviour and therefore it is only possible to observe the crude effect of a reform. In our study we also account for behavioural reactions or the so-called "second-round" labour effects. Therefore, we specify a model that allows behavioural reactions. The idea is that the household is allowed to decide which hours to work and also to change this decision. Using this information it is not only possible to calculate the distributional and labour supply effects separately. Moreover, it is possible to calculate the distributional effects with respect to the labour supply effects. In our study we use the behavioural ZEW microsimulation model (STSM) with an integrated household labour supply model. Our model has been used in earlier studies such as Arntz et al. (2004), Beninger et al. (2006), Beblo et al. (2004) and Jacobebbinghaus and Steiner (2003).

\footnotetext{
${ }^{2}$ The irregular one-time payments in the old SA were simulated as an 18 percent add-on to the transferred amount of the benefit.
} 


\section{Data and simulation sample}

The ZEW micro-simulation model is based on the micro data of the latest two waves from 2004 and 2005 of the German Socio Economic Panel (GSOEP). ${ }^{3}$

The GSOEP consists of nearly 12,000 households, and is a representative sample of private households with information amongst others on household income, hours of work and household characteristics. ${ }^{4}$

In our analysis we distinguish people as "flexible" to adjust labour supply and "inflexible" to adjust labour supply. Starting from the individual level a "flexible" person is in the working age of 20 to 65 years, does not participate in vocational training, military or civil services. Moreover, the individual should not be self-employed, on maternity leave, nor be on retirement. We continue our analysis on a selected simulation sample switching to household level and distinguishing the following Groups: In the first group, namely Group1, we select couple and single households that we define as "flexible". For the couple households both spouses are supposed to be "flexible". Group 2 contains only couples with one flexible spouse. Group 3 includes couples and singles with only inflexible people. Group 4 describes what we call the "selection remainder". In the simulation process Group 4 drops out, so we lose accuracy. To circumvent this problem we apply a correction of the household sample weights. ${ }^{5}$ These are people or households with missing information and non-response. For simulating the tax-benefit model without any behavioural adjustments we can use Group 1 to 3. For the behavioural model only the Group 1 and 2 can be considered, because at least one person within the household ought to be flexible. The following Table 1 illustrates the structure of the simulation sample.

Table 1: Weighted (unweighted) Simulation sample after the selection process

\begin{tabular}{|c|c|c|c|c|}
\hline group & 1 & 2 & 3 & $\mathrm{~N}$ \\
\hline couples & 8.71 Mill. (2603) & 3.56 Mill (949) & 5.53 Mill (1352) & 17.8 Mill (4904) \\
\hline singles & 8.21 Mill (1378) & -- & 10.08 Mill (1602) & 18.29 Mill (980) \\
\hline households & 16.92 Mill (3981) & 3.56 Mill (949) & 15.61 Mill (2954) & 36.09 Mill (7884) \\
\hline
\end{tabular}

Source: own calculations based on GSOEP 2004 and 2005

\section{Structural model of household labour supply}

In a standard theoretical framework a linear budget curve is derived from a continuum of

\footnotetext{
${ }^{3} \mathrm{~A}$ description of the German Socio Economic Panel is given by Haisken DeNew (2005)

${ }^{4}$ For people who are not working we lack the information about their gross hourly wage rate. To solve this we apply a wage regression with selection correction as proposed by Heckman (1976)

${ }^{5}$ See Appendix 4 in Jacobebbinghaus and Steiner (2003)
} 
hours. The indifference curve then displays the preferences of the household regarding hours to work and consumption. In the osculation point of both curves the optimal hours of work and optimal consumption is derived. Introducing a tax and benefit system, in particular the German tax and benefit system, the budget curve becomes nonlinear because of the complexity of the system (e.g. there exist kink points which produce complications in a continuous framework that are cumbersome to solve). ${ }^{6}$

Instead, we apply a discrete choice approach as suggested by van Soest (1995). This approach is favourable thereby that only a discrete number of hour points need to be considered from which the household can choose. As such, this framework copes with nonlinear budget curves circumventing the kink problem or allowing for non-convex budget sets. Furthermore, the empirical hours distribution of the households shows several peaks around particular hour categories suggesting that people might be bounded or restricted to a set of hours regarding the existing labour contracts and thus, supporting the discrete choice approach (See Table 2).

Table 2: Distribution of weekly hours of work for Group1

\begin{tabular}{|c|c|c|c|c|}
\hline weekly hours of work & \multicolumn{2}{|c|}{ singles } & \multicolumn{2}{c|}{ couples } \\
\hline & male & female & male & female \\
\hline $0-5[$ & $17 \%$ & $22.9 \%$ & $9.9 \%$ & $29.7 \%$ \\
$5,15[$ & $0.8 \%$ & $4.6 \%$ & $0.6 \%$ & $10 \%$ \\
$15-25[$ & $2 \%$ & $7.8 \%$ & $0.6 \%$ & $17.9 \%$ \\
$25-35[$ & $3.8 \%$ & $12.6 \%$ & $1.9 \%$ & $12.6 \%$ \\
$35-45[$ & $64.5 \%$ & $47.6 \%$ & $69.9 \%$ & $27.1 \%$ \\
$>=45$ & $11.8 \%$ & $4.5 \%$ & $17.2 \%$ & $2.7 \%$ \\
\hline average hours & $33.3 \mathrm{~h}$ & $26.6 \mathrm{~h}$ & $37.3 \mathrm{~h}$ & $20 \mathrm{~h}$ \\
\hline observations & 600 & 778 & 2603 & \\
\hline
\end{tabular}

Source: own calculations based on GSOEP 2004 and 2005

Referring to the hour distribution, we construct our hours set for women and men separately. For women we choose the weekly hour categories $\{0,10,20,30,40$, and 50\}. Category 0 describes the decision not to work, while 10, 20 and 30 define part-time work, 40 describes full-time employment and 50 defines overtime. For men we use a reduced set of hour categories because we nearly observe part-time work $\{0,20,40,50\}$, (see Table 2). For each hour category and the $24(4 \times 6)$ hour category combinations of couples with two flexible spouses we compute the respective outcomes like taxes, transfers, and disposable income by applying our microsimulation model. We assume that the individual hourly gross wage rate remains constant across the hour categories and that overtime if fully paid.

\footnotetext{
${ }^{6}$ For a discussion on the kink problem see Moffitt (1990) and for nonlinear budget sets see Hausman (1985)
} 
We use a structural model of household labour supply to transfer the outcomes in behavioural responses of the households. In this structural model we assume that the decision maker chooses the category with the highest utility compared to the other categories. This is our first identifying assumption. Furthermore, we assume that couples are regarded as one decision maker by jointly maximizing their utility. This model is considered a unitary model of household labour supply. ${ }^{7}$

We estimate household utility by using a translog utility function as proposed by van Soest (1995). For each individual we assume a weekly time endowment (TE) of 80 hours. This leads to $I m_{i}=T E-h_{i}$ and $I f_{i}=T E-h_{i}$ where $I m$ indicates the weekly leisure of a male and If the weekly leisure of a female of the respective household $i$.

$$
U_{k}\left(x_{k}\right)=x_{k}^{\prime} A x_{k}+\beta^{\prime} x_{k}+\varepsilon_{k}
$$

$U_{k}$ represents the utility of category $k$. The column vector $x_{k}$ includes monthly disposable income and leisure of the household in natural logarithm $\left(\log y_{i}, \log \operatorname{lm} i, \log l f i\right)$. The unobserved part is defined by $\varepsilon_{k}$ which is assumed to be iid . The symmetric $3 \times 3$ matrix A contains the coefficients of the interactions and quadratic terms of the included variables and the vector $\beta$ contains the coefficients of the linear terms. The probability of a decision maker now choosing category $\mathrm{k}$ instead of category $\mathrm{I}$ is given by:

$$
\operatorname{Pr}_{k}=\operatorname{Pr}\left(U_{k}>U_{l}\right)=\operatorname{Pr}\left(\left(x_{k}^{\prime} A x_{k}+\beta^{\prime} x_{k}\right)-\left(x_{l}^{\prime} A x_{l}+\beta^{\prime} x_{l}\right)>\varepsilon_{l}-\varepsilon_{k}\right), \forall l \neq k
$$

In order to solve the equation it is necessary to make a distributional assumption about the unobserved part of the utility function. In particular, it is assumed that the density for each unobserved part of the utility function is

$$
f\left(\varepsilon_{j}\right)=\exp \left(-\varepsilon_{j}\right) \cdot \exp \left(-\exp \left(-\varepsilon_{j}\right)\right)
$$

and the c.d.f.

\footnotetext{
${ }^{7}$ An extension of that would be to focus on intra-household sharing of incomes which has been done by Beninger and Laisney (2002).
} 


$$
F\left(\varepsilon_{j}\right)=\exp \left(-\exp \left(-\varepsilon_{j}\right)\right)
$$

The distribution is called Gumbel or type I extreme value distribution. While assuming this distribution for the unobserved part, it can be shown that the difference of the unobserved parts follows a logit distribution (McFadden 1974, 2001). The probability of choosing category $k$ can thus be written as

$$
\operatorname{Pr}_{k}\left(U_{k}>U_{l}\right)=\operatorname{Pr}(X=k)=\frac{\exp \left(x_{k}^{\prime} A x_{k}+\beta^{\prime} x_{k}\right)}{\sum_{m} \exp \left(x_{m}^{\prime} A x_{m}+\beta^{\prime} x_{m}\right)}, \forall l \neq k
$$

The parameters of the conditional logit model are then estimated by maximum likelihood, assuming the IIA-assumption holds (See Equation 6).

$$
L=\prod_{i=1}^{n} \prod_{j=1}^{m} \operatorname{Pr}(H=j)^{d_{i j}}
$$

Where $\operatorname{Pr}(H=j)$ describes the choice probability of category $j$, and $d_{i j}$ is defined as indicator which takes the value $d_{i j}=1$ if household $i$ has chosen category $j$ and 0 if not.

\section{Distribution Analysis}

Before applying a distributional analysis, it is necessary to distinguish two mechanisms. The distributional effects consist of the direct effects caused by the change of the disposable incomes and the indirect effects that are due to the re-financing of the benefit payment. Latter results from the fact that the UB II is tax financed and so the aim would be also to target who will have to carry the redistribution costs. This would demand a general equilibrium model, because several carryover effects would have to be taken into account, which is rather difficult in a partial equilibrium framework. So the question is to focus either on the disposable income or the household consumption to measure the direct effects. The GSOEP does not provide information on non-earned income, consumption or accumulated rights to pensions. Thus, we focus our analysis on comparing the disposable household incomes that are calculated with our ZEW-microsimulation model. The disposable household incomes are then modified by equivalence scales to account for differences in the size of the households. The same context is also used by the 
Government and the European Union (EU). To check for robustness we apply different concepts of equivalence scales, like the international expert scale, OECD and modified OECD. The concepts we use for measuring the income inequality are the Gini-coefficient and the measures proposed by Atkinson (1970). In general, the income gainers and losers are detected by performing a percentile analysis; while specific a poverty analysis focuses on that part of the income distribution that is below a minimal standard. The problem is that there exists no real consensus about what defines a minimal standard, although there are several definitions of understanding poverty ${ }^{8}$. We use the measures of Foster, Greer and Thorbeeke (1984) that also belong to the family of axiomatic poverty measures that have been established by Sen (1976). We use FGT (0), FGT (1) and FGT (2). FGT (0) displays the poverty rate, calculating the number of heads below the minimal standard. FGT (1) defines the standardised poverty gap ratio and FGT (2) the squared standardised poverty gap ratio. Because the latter measures the squared gap of the income to the poverty line, higher income gaps receive a higher weight.

In a first step of our analysis, we calculate the disposable equivalence income relying to the scales mentioned above. This defines our status quo, or the benchmark scenario. In a second step the changes of the regime are applied and the counterfactual incomes are calculated. For the following description of the methodology that is used we define the income in the status quo as:

$$
y v_{i}^{0}
$$

For the reform scenario we define respectively:

$$
y v_{i}^{1}
$$

where the superscript 1 now indicates the reform scenario. As this method does not take into account the behavioural adjustments we call it simple simulation. This "simple simulation" produces the "morning-after effect". Considering behavioural reactions makes the method more complicated as we will demonstrate in the following.

The conditional logit estimation produces a probabilistic distribution on the discrete hour categories as discussed in Section 3. As such, it is not clear how to compare disposable

\footnotetext{
${ }^{8}$ See Sen (1983) for example.
} 
incomes before and after the reform. In this framework the standard formulas for inequality and poverty measures cannot be applied. One method would be to use the expected income which results from the probabilities for each category multiplied with the respective disposable income calculated at this category. Other methods would be the random sampling method or the pseudo distribution method. For the random sampling method a specified number of incomes are drawn from the underlying income distribution and the measures are calculated as averages of the draws. The pseudo distribution method is characterised thereby that the disposable income for each category is treated as a separate observation. This establishes the pseudo distribution with household weights relative to the estimated probability of the category. Creedy et al. (2004) find that that the expected income method results in a less accurate approximation of the true inequality measures compared to random sampling methods and the pseudo distribution method. In contrast, the pseudo distribution method leads to outcomes that converge quickly to the true values that had been simulated. According to Creedy et al. (2004) the pseudo distribution method is superior to the random sampling method. Thus, we also apply the pseudo distribution method. This leads to the following structure:

$$
\begin{aligned}
& y v_{i j}^{0}=f\left(H_{i}=j ; R=0 ; x_{i j}\right) \\
& y v_{i j}^{1}=f\left(H_{i}=j ; R=1 ; x_{i j}\right)
\end{aligned}
$$

where the subscript $i$ indicates the household and $j$ the category. So the disposable income $y v_{i j}^{R}$ is a function of the chosen hour category, the scenario, where $\mathrm{R}=0$ indicates the status quo and some individual and category specific characteristics, expressed in $x_{i j}$ The pseudo distribution method is applied by multiplying the household weights with the estimated probabilities of the respective hour category for the status quo and the reform scenario with $R=0,1$ (see Equation 11).

hhweightsp $_{i j}^{R}=$ hhweights $_{i} \cdot p_{i j}^{R}$, with $\sum_{j=1}^{m}$ hhweightsp $_{i j}^{R}=$ hhweights $_{i}$

We define this method as "labour income simulation", because it refers to the estimation of the household labour supply model which produces the hour probabilities to measure 
behavioural reactions. In the following, we distinguish the results as simulation without behavioural reactions (nob) and simulation with behavioural reactions (wb). For the simulation without behavioural reactions we apply the disposable income $y v_{\text {if }}^{1}$ of the reform scenario and the modified household weights of the status quo hhweightsp $p_{i j}^{0}$ (see Equation 12). In order to analyse the behavioural reactions, we use the disposable income of the reform scenario $y v_{\text {if }}^{1}$ and the modified household weights of the reform scenario hhweightsp ${ }_{i j}^{1}$ (see Equation 13). The difference of Equation (13) and Equation (12) evolves the pure behavioural effect.

$$
\begin{aligned}
& y v_{i j}^{10}=y v_{i j}^{1} \cdot \text { hhweightsp }_{i j}^{0} \\
& y v_{i j}^{11}=y v_{i j}^{1} \cdot \text { hhweightsp }_{i j}^{1}
\end{aligned}
$$

\section{RESULTS}

\section{Household labour supply effects}

As Table 2 illustrated, we detect differences in the distribution of the hours of work between single and couple and within single households between men and women. Therefore we estimate our conditional logit model separately for couples, single women and single men, and for couple households with only one flexible spouse. We interact the category-specific variables income and leisure with category invariant variables like age, age squared, education level, region, and nationality. For females we additionally interact with children in the age till 6 years, from 7 to 16 years and from 17 years. In addition, we build dummy variables for full-time employment for both sexes and for women also for part-time employment to cover the fix costs of working part or fulltime. The results for couples show that most of the variables are highly significant. We check the theoretical assumption of concavity by analysing the derivations and the minors of the Hessian matrices. The demanded theoretical quality of our model that utility rises with a decreasing marginal rate with higher leisure and with higher income is fulfilled. We continue estimating the labour supply elasticities numerically by rising the gross earned income about one percent (See Table 3). If the gross-income of the male spouse is increased by one percent, the woman reduces her participation about 0.02 percentage points while she reduces working hours about 0.05 percent. This result implies that if the male's income 
increases the woman substitutes work with leisure. One explanation could be the taxsplitting system which produces higher marginal tax rates for women if the husband is working fulltime or that women are more likely to take care of their children. The male spouse increases his participation about 0.16 percentage points and his working hours about 0.24 percent if his gross income increases about one percent. He also increases his participation and his working time if the gross income of the female spouse increases. One explanation for this result could be that male spouses could feel themselves in competition with their successful women. For single households the elasticities are quite similar for single women and single men with 0.17 and 0.18 percentage points, while the hours effects are much higher for single women with 0.38 to 0.23 percent for men. This is very similar for couples with one inflexible partner while the hour effects are 0.2 for men and 0.36 .

Table 3: Labour supply elasticities

\begin{tabular}{|l|c|c|c|c|}
\hline & \multicolumn{2}{|c|}{$\begin{array}{c}\text { participation effect } \\
\text { (in percentage points) }\end{array}$} & \multicolumn{2}{|c|}{$\begin{array}{c}\text { hours effect } \\
\text { (in percentage) }\end{array}$} \\
\hline & male & female & male & female \\
\hline couples & & & & \\
income male spouse (+ 1 percent) & 0.16 & -0.02 & 0.24 & -0.05 \\
income female spouse (+ 1 percent) & 0.02 & 0.14 & 0.03 & 0.37 \\
\hline $\begin{array}{l}\text { singles } \\
\text { income (+ 1 percent) }\end{array}$ & 0.17 & 0.18 & 0.23 & 0.38 \\
\hline couples with one flexible spouse & & & & \\
income (+ 1 percent) & 0.17 & 0.18 & 0.2 & 0.38 \\
\hline
\end{tabular}

Source: own calculations based on GSOEP 2004 and 2005

In a next step we account for the labour supply effects that are likely to result from the reform by comparing the participation rate in the status quo with the reform scenario. The results are presented in Table 4. The negative participation effects are mainly dominated by couples with one flexible spouse. Among these households, especially women reduce their participation. In general, the negative effects are driven by households who become eligible for UB II in the reform scenario and who did not receive any benefits in the status quo. Negative effects are also found for single mothers and married women if children are in the household. This seems plausible, because usually women have to take care of the children. In an opposite direction, positive effects are found for single men and single women and for couples without children. The total effects do not significantly vary from zero. 
Table 4: participation effects in Western and Eastern Germany

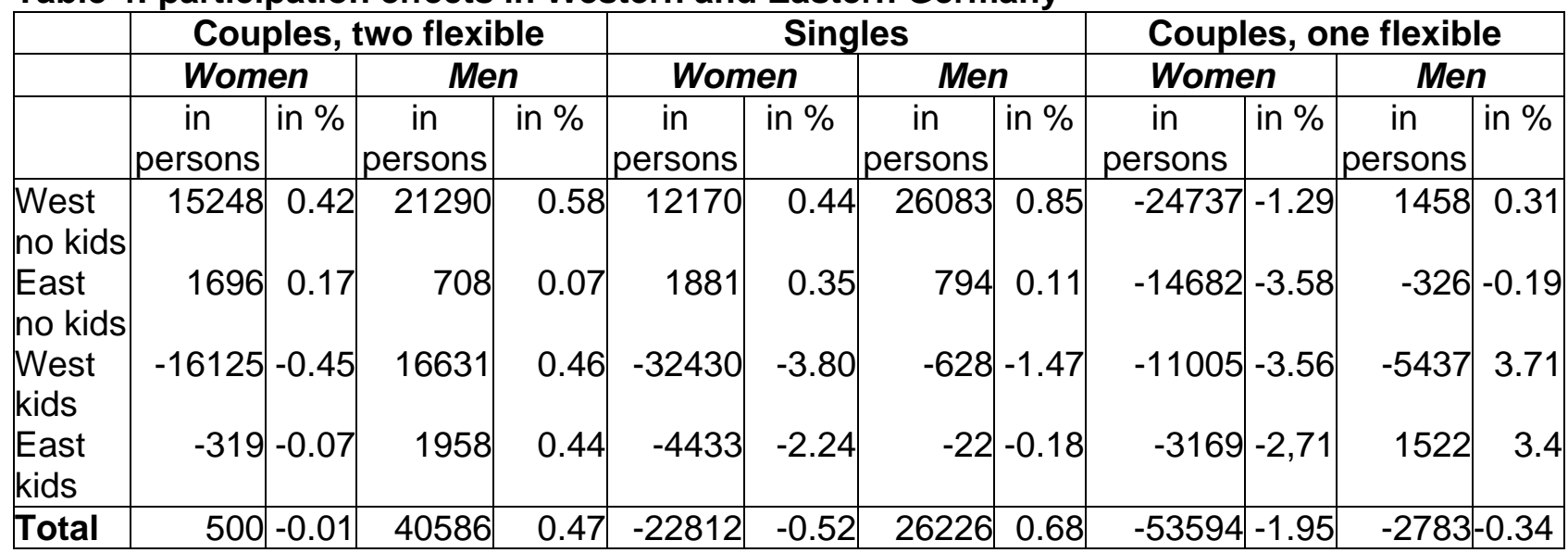

Source: own calculations based on GSOEP 2004 and 2005

\section{Results of the Distribution Analysis}

Having established our estimation model we proceed with the distribution analysis. As mentioned in Section 4 we conduct our analysis with the "labour income simulation" method. In a first step we apply our analysis to the whole simulation sample. In a next step we build subgroups for different states. The first subgroup we specify as "Group A". This Group contains all people who are "Affected" by the reform. Furthermore, we create subgroups for the people who received UA, SA, also including people who received both, and people who received no benefits in the status quo. ${ }^{9}$ The analysis of the subgroups for UA and SA include people that become eligible for UB II, people who pass over to the "new" SA and people who lose their entitlement.

In the following the results are based on the international expert scale, because it is the most commonly used scale. Furthermore, applying the international expert scale reduces the equivalence income less if the number of people within the household increases. Due to the fact that the results show an observable sensitivity according to the equivalence scale that has been chosen, Atkinson (1998). Therefore, we extend our analysis also to the OECD and the modified OECD scale. ${ }^{10}$

As shown in Figure 3 the rounded Gini-coefficient remains unchanged for the entire population at 0.27 while a reduction of inequality can be measured by looking at "Group A" as we had expected.

\footnotetext{
${ }^{9}$ The tables with the results for the other subgroups can be received by the authors upon request

${ }^{10}$ The results for the different scales can be received by the authors upon request
} 

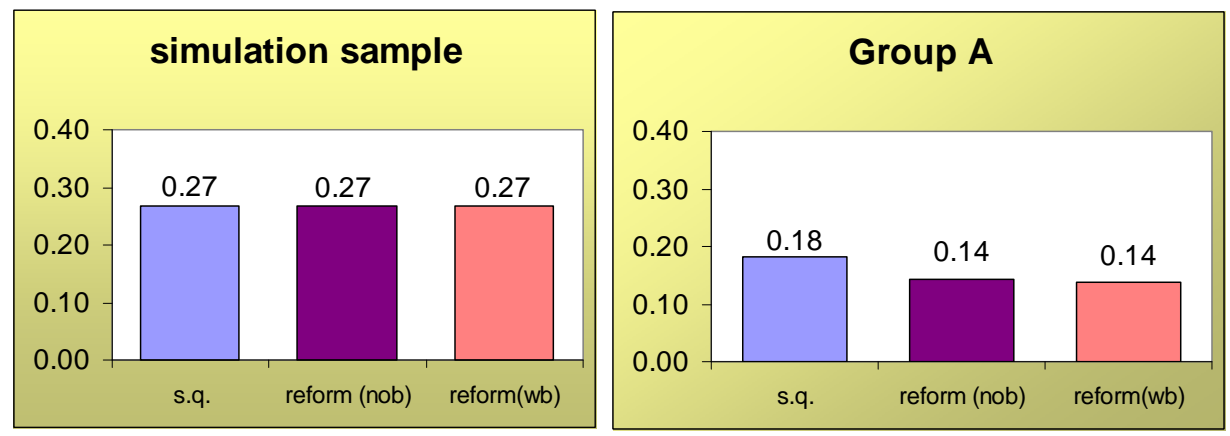

Figure 3: Gini-coefficient

Here the Gini-coefficient falls from 0.18 to 0.14 . This result is very similar for people with former UA and even stronger for people without benefits in the status quo. The Ginicoefficient for people with SA slightly increases. The Atkinson measures also confirm a reduction of income inequality for "Group $A$ " and also for the sample simulation. The effects are in general stronger for the Atkinson measures as compared to the Ginicoefficient (see Figure 4). These general results reflect the quality of the Gini-coefficient, because it is more sensitive to deciles with more observations. The Atkinson measures on the other side are more sensitive to changes in the bottom deciles; therefore we observe stronger effects. ${ }^{11}$
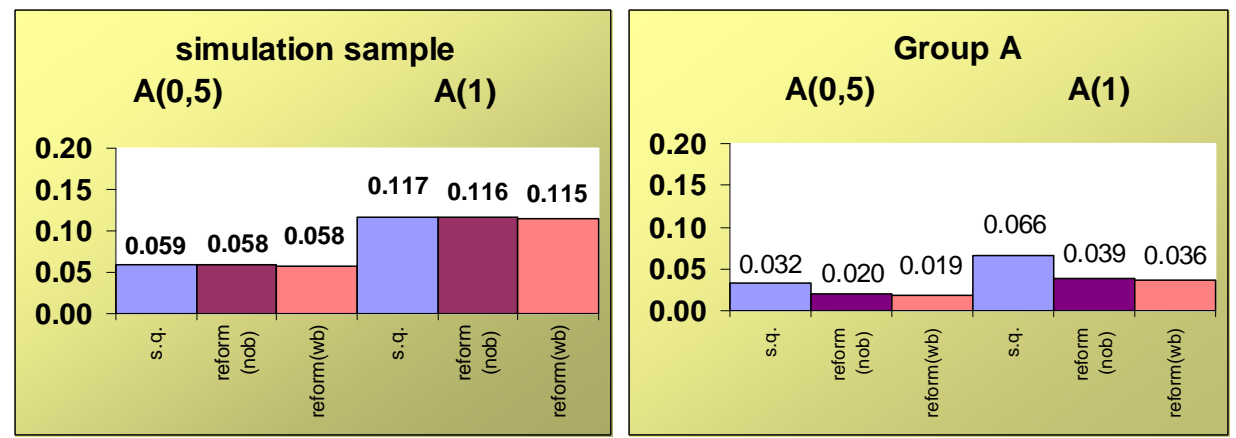

Figure 4: Atkinson measures

For people with UA the Atkinson measures also show a reduction of income inequality within that subgroup while for people with SA, the Atkinson measures denote a slight increase in income inequality. These effects become more explicit with behavioural adjustments $(\mathrm{wb})$. In the following poverty analysis the results show the same directions as the inequality analysis. The head count ratio (FGT0) of the sample population, which indicates the poverty rate, slightly declines and more distinct for "Group A". The standardised poverty gap ratio (FGT1) and the squared standardised poverty gap ratio

\footnotetext{
${ }^{11}$ For a discussion on the properties of the Gini-coefficient see Cowell (1985), Blackorby and Donaldson (1978), Atkinson (1970) and Sen (1973)
} 
(FGT2) decline for the whole simulation sample and within "Group A" (see Figure 5). These results suggest that the distance to the poverty line becomes smaller, especially for Group A. Here the share of people below the poverty line is reduced by 15 percent.

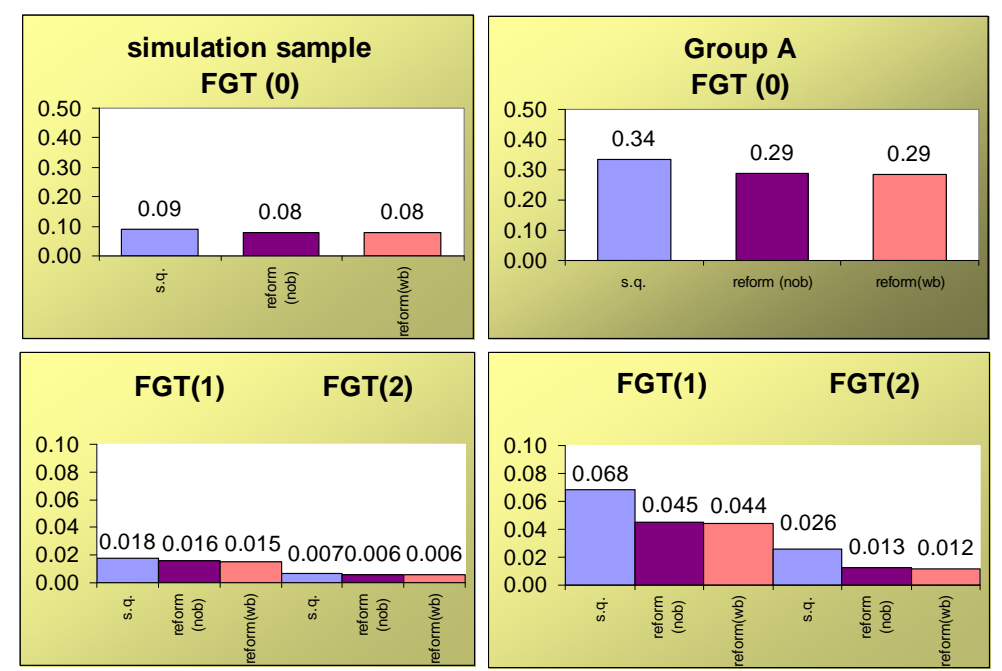

Figure 5: Foster-Greer-Thorbeeke measures

For people with UA, the poverty rate is increasing about two percentage points while for recipients of former SA there is a reduction of two percentage points. The results for UA that the income inequality has declined combined with an increase of the poverty rate, leads to the conclusion that redistribution from the top to the bottom must have taken place. This becomes clearer by looking at the percentile analysis (see Figure 6).
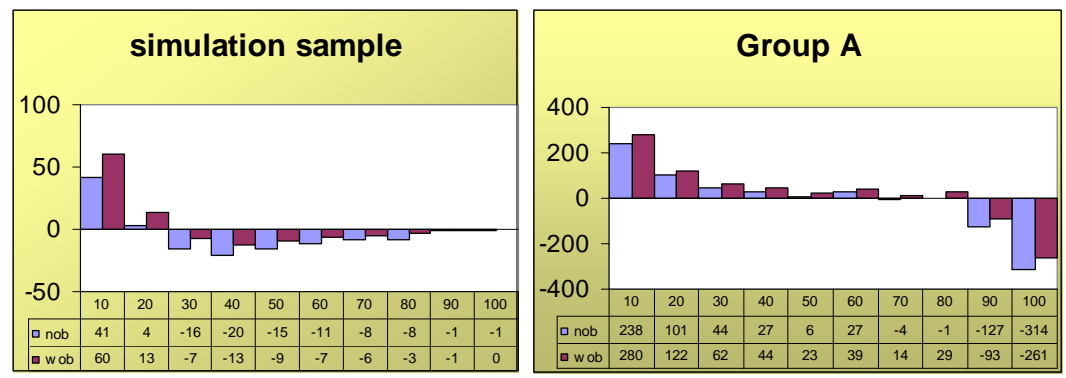

Figure 6: Percentile analysis

As we can see from the percentile analysis for the simulation sample, the two bottom deciles are the income gainers of the reform. The income losers are detected in the 3th to 8th decile. Within the Group A, the top two deciles are losing the most income per capita while the bottoms are gaining most income. These income profits of the bottom two deciles diminish until the 8th decile. The income losses found in the higher deciles are mainly driven by former recipients of higher UA.

If we consider the number of children in a household, we detect that the gains are 
increasing with the number of children which is consistent for the entire population and "Group A" (see Figure 7). This finding results from the fact, that benefit payments for children - these are calculated relatively to the basic benefit - have become more generous due to the higher basic benefit rate.

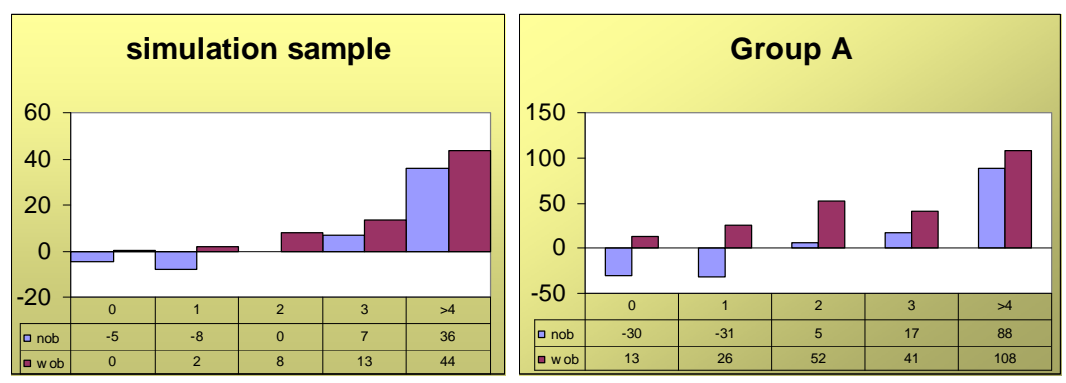

Figure 7: Children analysis

All together, we can summarize that we identify most of the losers in the group of the people with former UA. Here, we identify six deciles (seven deciles) as income losers with behavioural response (without behavioural response). This finding is agreement with Schulte (2004), Blos and Rudolph (2005), Becker and Hauser (2006). In contrast, we find reform winners in the subgroup of people with former SA for almost all deciles. This can be explained by the less restrictive income withdrawal rates and the higher rates for children as mentioned above. In addition, we observe the strongest reform winners in the group of people without benefit payments in the status quo. While the former result for SA is plausible and in the direction we expected, the latter result is - although plausible as wellalso influenced by the structure of our tax-benefit model: The GSOEP contains only insufficient information on the non-earned income. We only observe the yearly interest incomes together with incomes from dividends. So, we assume an interest rate of 3 percent to recalculate the potential capital assets. These calculated assets serve us as basis for the wealth test. This leads to the result that a lot of people become eligible because they were not entitled for UA and they had too many private assets by law to receive SA. Within this group nine out of ten deciles are winning, so this group of people become the strongest income gainers of the reform. A main aspect of our analysis was the consideration of behavourial responses. A such, the results show, that in general, taking into account behavioural reactions mitigate the negative distribution effects of the reform on one side and boost the positive effects on the other side. This implies that the households adjust their behaviour in an optimal way to improve their income situation. 


\section{CONCLUSION}

Our distribution analysis of the "Hartz-4-Reform" is the first attempt to cover the entire population. Furthermore, we are the first who account for the "second-round" effects by allowing behavioural adjustments. We used the pseudo-distribution method which is a simple and sufficient approach in a probabilistic framework when focussing on issues of income distribution.

The main results of our analysis are the following: The introduction of UB II has led to a consolidation of the benefit system. The presumption that people who used to receive high UA-benefits because they had higher earnings (before unemployment) are losing most is confirmed. We find that six deciles (seven deciles) are losing income as a consequence of the reform with consideration of behavioural effects (without behavioural effects). Our results correspond with the findings of other studies like Becker and Hauser (2006), Schulte (2004) and Blos and Rudolph (2005) regarding the recipients of former UA. We identify reform winners in the subgroups of (1) former recipients of social assistance and of (2) new recipients. The largest gains accrue to households with many children and to households who have not been eligible for any benefits before. These households become eligible, because of the less restrictive non-earned-income test compared to the old social assistance. For the whole group of benefit recipients, namely "Group A", we find a reduction of the income inequality accompanied by a positive effect on poverty measures. This effect is in line with the theoretical considerations. The new benefit system has a tendency to equalize the transfer payments on a level that is slightly higher than the old social assistance level. These results are also confirmed by the labour supply effects. We find negative participation effects for women with children in couple and single households. In the opposite, couples without children, single men and women without children increase their participation. These contrary effects nearly cancel out and are not significant in either direction. Thus, the net employment effect of the reform is negligible. 


\section{REFERENCES}

Aaberge, Rolf, Ugo Colombino and Steinar Storm (2000): "Labor Supply Responses and Welfare Effects from Replacing Current Tax Rules by a Flat Tax: Empirical Evidence from Italy, Norway and Sweden", Journal of Population Economics.

Arntz, Melanie, Michael Feil and Alexander Spermann (2003): "Die Arbeitsangebotseffekte der neuen Mini- und Midijobs -- eine ex-ante Evaluation“, Mitteilungen aus der Arbeitsmarkt- und Berufsforschung 36, 271-290.

Atkinson, Anthony Barnes (1970): "On the Measurement of Inequality', Journal of Economic Theory 2", 244-263.

Beblo, Miriam, Denis Beninger and François Laisney (2004): "Family Tax Splitting: A Microsimulation of its Potential Labour Supply and Intra-Household Welfare Effects in Germany", Applied Economics Quarterly, 50(3), 233-240.

Beninger, Denis, François Laisney and Miriam Beblo (2007): "Welfare Analysis of Fiscal Reforms: Does the Representation of the Family Decision Process Matter? Evidence for Germany", Journal of Population Economics.

Becker, Irene and Richard Hauser (2006): "Verteilungseffekte der Hartz-IV-Reform. Ergebnisse von Simulationsanalysen", edition Sigma. Berlin.

Beninger Denis and François Laisney (2002): "Comparison Between Unitary and Collective Models of Household Labour Supply with Taxation", Discussion Paper 0264, ZEW, Mannheim.

Blos, Kerstin (2006): "Haushalte im Umfeld des SGB II", IAB-Forschungsbericht 19/2006. Nürnberg.

Blos, Kerstin and Helmut Rudolph (2005),"'Simulationsrechnungen zum Arbeitslosengeld II: Verlierer, aber auch Gewinner", IAB-Kurzbericht 17/2005. Nürnberg.

Blundell Richard, Alan Duncan, Julian McCrae and Costas Meghir (2000): "The Labour Market Impact of the Working Families-Tax Credit", Fiscal Studies 21, 75-104.

Creedy, John and Guyonne Kalb (2005): "Discrete hours labour supply modelling: specification, estimation and simulation", Journal of Economc Surveys, 19, 697-734.

Creedy, John and Alan S. Duncan (2002): "Behavioural mircosimulation with labour supply responses", Journal of Economic Surveys, 16, 1-39.

Creedy, John, Guyonne Kalb and Rosanna Scutella (2004): "Evaluating the income redistribution effects of tax reform in discrete hours models", Chapter 9 in Amiel Y. and Bishop J.A. (Eds.) Studies on Economic Well-Being: Essays in Honor of John P. Formby, included in the series Research on Economic Inequality, 12, 199-226 
Creedy, John, Guyonne Kalb and Rosanna Scutella (2003): "Income distribution in discrete hours behavioural microsimulation models: An illustration of the labour supply and distributional effects of social transfers", Melbourne Institute Working Paper, 23/03 Cowell, Frank Alan (1995): Measuring Inequality, $2^{\text {nd }}$ ed. London et al.

Christensen, Laurits R., Dale Jorgenson and Lawrence Lau (1971): "Conjugate Duality and the Transcendental Logarithmic Funktion", Econometrica 39, 255-256

Van Soest Arthur and Marcel Das (2001): "Family labour supply and proposed tax reforms in the Netherlands", De Economist.

Foster, James, Joel Greer and Erik Thorbeeke (1984): “A Class of Decomposable Poverty Measures', Econometrica 52, 761-766.

Gerfin, Michael and Robert E. Leu (2003): "The Impact of In-Work Benefits on Poverty and Household Labour Supply - A Simulation Study for Switzerland", IZA Discussion paper 762.

Haisken De-New, John and Joachim R. Frick (2005): DTC-Desktop Compendium to the German Socio-Economic Panel (GSOEP)

Hausman, Jerry Allen and Daniel McFadden (1984): "Specification Tests for the Multinomial Logit Model", Econometrica, 52, 1219-1240.

Heckman, James (1976): "The Common Structure of Statistical Models of Truncation, Sample Selection and Limited Dependent Variables and a Simple Estimator for Such Models", Annals of Economic and Social Measurement, 5, 475-492.

Hoynes, Hilary Williamson (1996): "Welfare Transfers in Two Parent Families: Labour Supply and Welfare Participation Under AFDC-UP", Econometrica 64, 295- 332. Jacobebbinghaus, Peter and Viktor Steiner (2003): "Reforming Social Welfare as We Know It? A Microsimulation Study for Germany", Discussion Paper 03-33, ZEW, Mannheim.

Keane, Michael P. and Robert Moffitt (1998): "A Structural Model of Multiple Welfare Program Participation and Labour Supply", International Economic Review 39, 553589.

Labeaga, José María, Xisco Oliver and Amedeo Spadaro (2005): "Discrete Choice Models of Labour Supply, Behavioural Microsimulation and the Spanish Tax Reforms", PSE Working Paper 13/2005.

McFadden, Daniel (1974): "Conditional Logit Analysis of Quantitative Choice Behavior", in Zarembka P (ed.): Frontiers in Econometrics, New York, Acad. Pr., 105-142 Moffitt, Robert (1990): "The Econometrics of Kinked Budget Constraints", Journal of Economic Perspectives, Vol. 4, No. 2, 119-139. 
Schulte, Jan (2004): „Arbeitslosengeld II und Arbeitslosenhilfe: Gewinner und Verlierer. Eine Schä tzung der Nettoeinkommenseffekte von Hartz IV“, FU Berlin Diskussionsbeiträge 29.

Sen, Amartya Kumar (1973): On Economic Inequality, Oxford.

Sen, Amarty Kumar (1976): "Poverty: An Ordinal Approach to Measurement', Econometrica 44, 219-231.

Van Soest, Arthur (1995): "Structural models of family labor supply: a discrete choice approach", Journal of Human Resources 30, 63-88. 